\title{
A 7-Year-Old Boy with Light Cupula of the Horizontal Semicircular Canal
}

\author{
Hiroaki Ichijo \\ Ichijo Ear, Nose and Throat Clinic, Hirosaki, Japan \\ Email: hiro3387@mvj.biglobe.ne.jp \\ Received 9 February 2014; revised 1 March 2014; accepted 11 March 2014 \\ Copyright (C) 2014 by author and Scientific Research Publishing Inc. \\ This work is licensed under the Creative Commons Attribution International License (CC BY). \\ http://creativecommons.org/licenses/by/4.0/ \\ (c) (i) Open Access
}

\begin{abstract}
Report of childhood positional vertigo is very rare. We present a 7-year-old boy who revealed persistent direction-changing geotropic positional nystagmus. In the supine position, horizontal nystagmus toward the left continued as long as the position was maintained. However, it ceased when the head was turned to the right side by $45^{\circ}$. With greater head turn (right-ear-down), nystagmus toward the right lasted for more than 1 minute. In the left-ear-down position, horizontal nystagmus toward the left occurred and lasted for more than 1 minute. After the disappearance of positional nystagmus, we detected canal paresis of the right ear by caloric test. We considered that the pathophysiology of the persistent type of geotropic nystagmus is a result of light debris cupulolithiasis of the horizontal canal.
\end{abstract}

\section{Keywords}

\section{Light Cupula; Positional Nystagmus; Child; Video-Oculography}

\section{Introduction}

Positional vertigo is the most common disorder of the peripheral vestibular system. Several studies have suggested that female sufferers outnumber males by more than 2 to 1 [1] [2], and the age of onset is usually during the fifth through seventh decades of life [3] [4]. Most patients are more than 18 years old [5] [6], and reports of childhood onset are very rare. Recently, we experienced a 7-year-old boy who revealed persistent directionchanging geotropic positional nystagmus. We describe the laboratory findings with consideration of the pathophysiology. This case is the second youngest reported, as far as we are aware [7].

\section{Case Report}

In the early afternoon on 16 November, 2011, a 7-year-old boy (date of birth: 23 August, 2004) experienced se- 
vere vertigo while having lunch in school. He complained of neither cochlear symptoms nor a headache. After returning home, the spinning sensation did not improve and led to vomiting. The next day, his parents brought him to a general hospital. A pediatrician ordered an urgent brain magnetic resonance imaging (MRI); however, it showed no abnormality. On 19 November, 2011, the patient was introduced to our hospital. On initial physical examination, tympanic membranes, nasal cavity and oral cavity were normal. Height was $127 \mathrm{~cm}$ and weight was $31 \mathrm{~kg}$. Mild gaze nystagmus toward the left was observed in a sitting position. We performed supine roll test in the dark with the patients' eyes open using an infrared charge-coupled device camera. In a supine position, horizontal nystagmus toward the left continued as long as the position was maintained. However, it ceased when the head was turned to the right by $45^{\circ}$ (we measured the angle using a big protractor). With greater head turn (right-ear-down), nystagmus toward the right lasted for more than 1 minute. In the left-ear-down position, horizontal nystagmus toward the left occurred and lasted for more than 1 minute. Namely, the patient showed persistent direction-changing geotropic positional nystagmus. In a sitting position, mild leftward horizontal nystagmus was observed. In the nose-down position, rightward horizontal/vertical (downward) nystagmus occurred. Eye movements were recorded and converted to digital data. Using ImageJ 1.36 and a Macintosh computer (Mac OS 10.6.2), 2-dimensional video-oculography was performed. For analysis of horizontal and vertical components, the XY center of the pupil was calculated [8]. Video-oculography results are shown in Figures 1-3. The accuracy of video-oculography is equivalent to that of a scleral search coil system [9]. Slow-phase velocity in the left-ear-down position was $32 \%$, that in the supine position was $10 \%$, and that in the right-ear-down position was $8 \%$ s. In a supine position, we tested visual suppression by instructing the patient to fixate on a small light-emitting diode. As a result, the nystagmus was remarkably suppressed.

No treatment was performed, but instead it was suggested that the patient sleep with the upper body elevated (Fowler's position). Since vertigo and positional nystagmus had disappeared on 28 November, 2011, we performed caloric test. One $\mathrm{ml}$ of iced water was slowly poured into the left external auditory canal in the rightear-down position using a small syringe, taking $20 \mathrm{~s}$. After pouring, the subject was rotated to a supine position, and vice versa. The response of the left ear was good (maximum slow-phase velocity was $29^{\circ} / \mathrm{s}$ ), while that of the right ear was poor (maximum slow-phase velocity was $7^{\circ} / \mathrm{s}$ ).

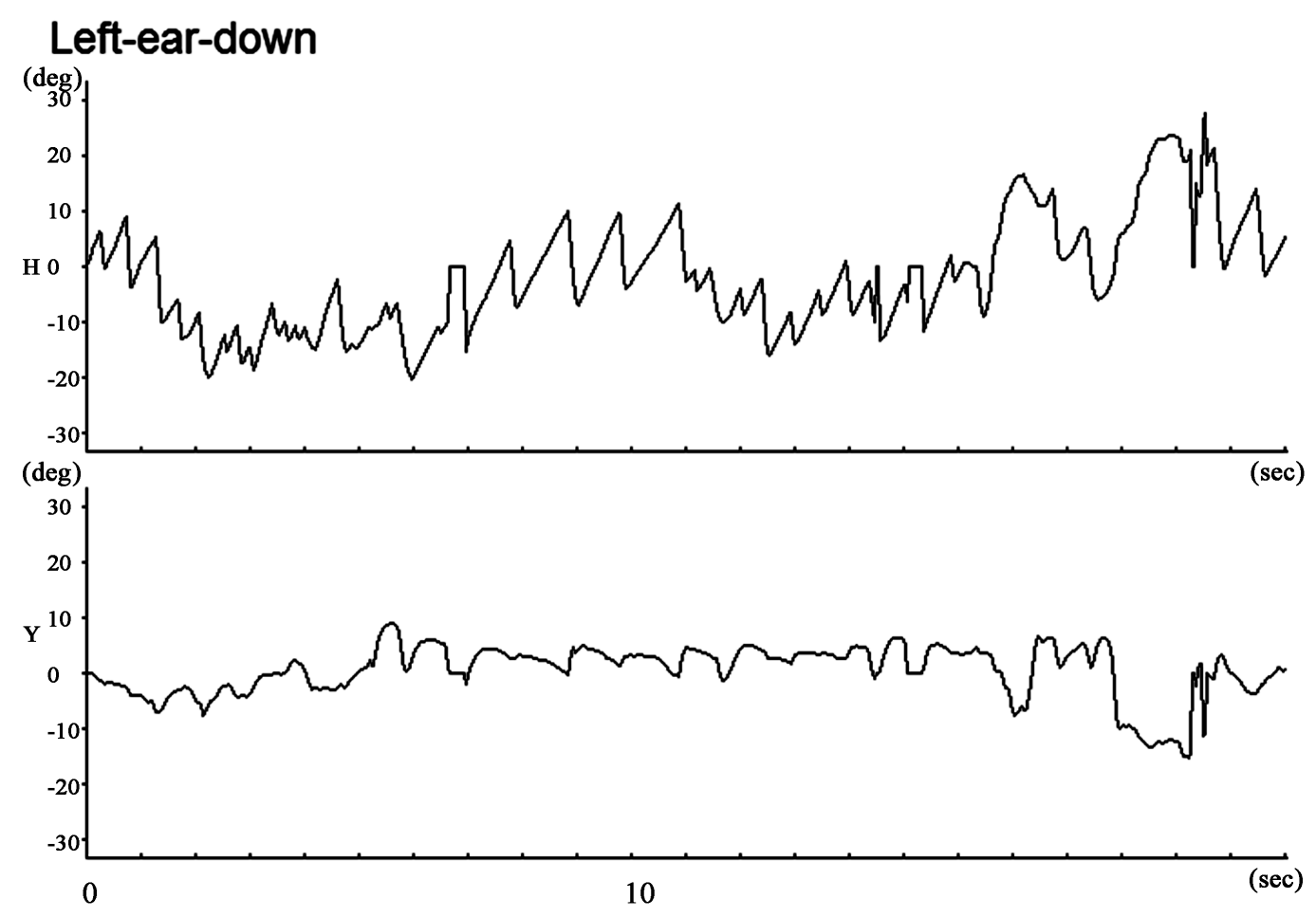

Figure 1. Video-oculography (position trace). In the left-ear-down position, horizontal nystagmus toward the left lasted for more than 1 minute. The upward deflections in horizontal $(\mathrm{H})$ and vertical (V) eye movements are indicated as being toward the right and upward, respectively. 


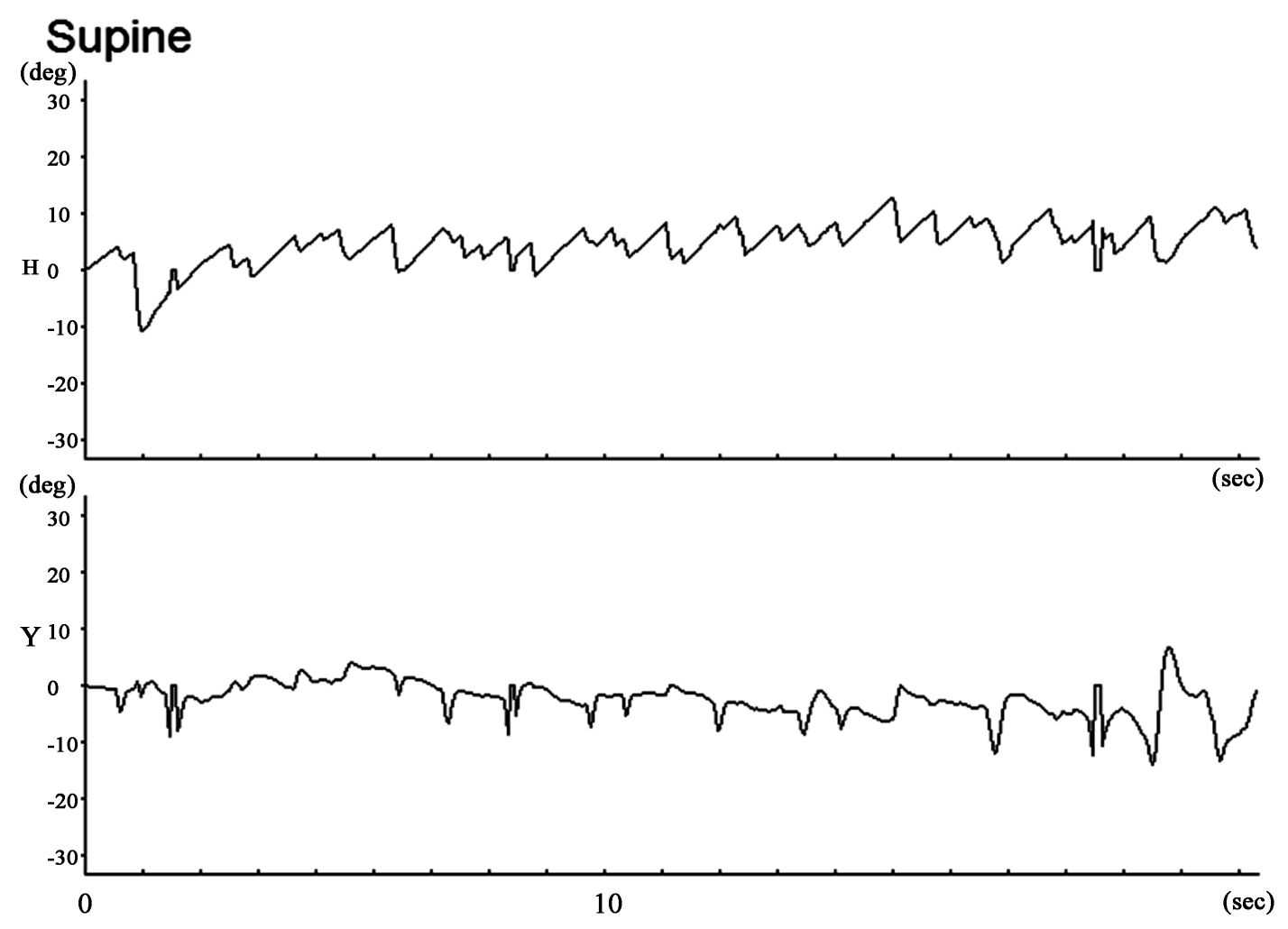

Figure 2. Video-oculography (position trace). In the supine position, horizontal nystagmus toward the left continued as long as the position was maintained. H, horizontal component; V, vertical component.

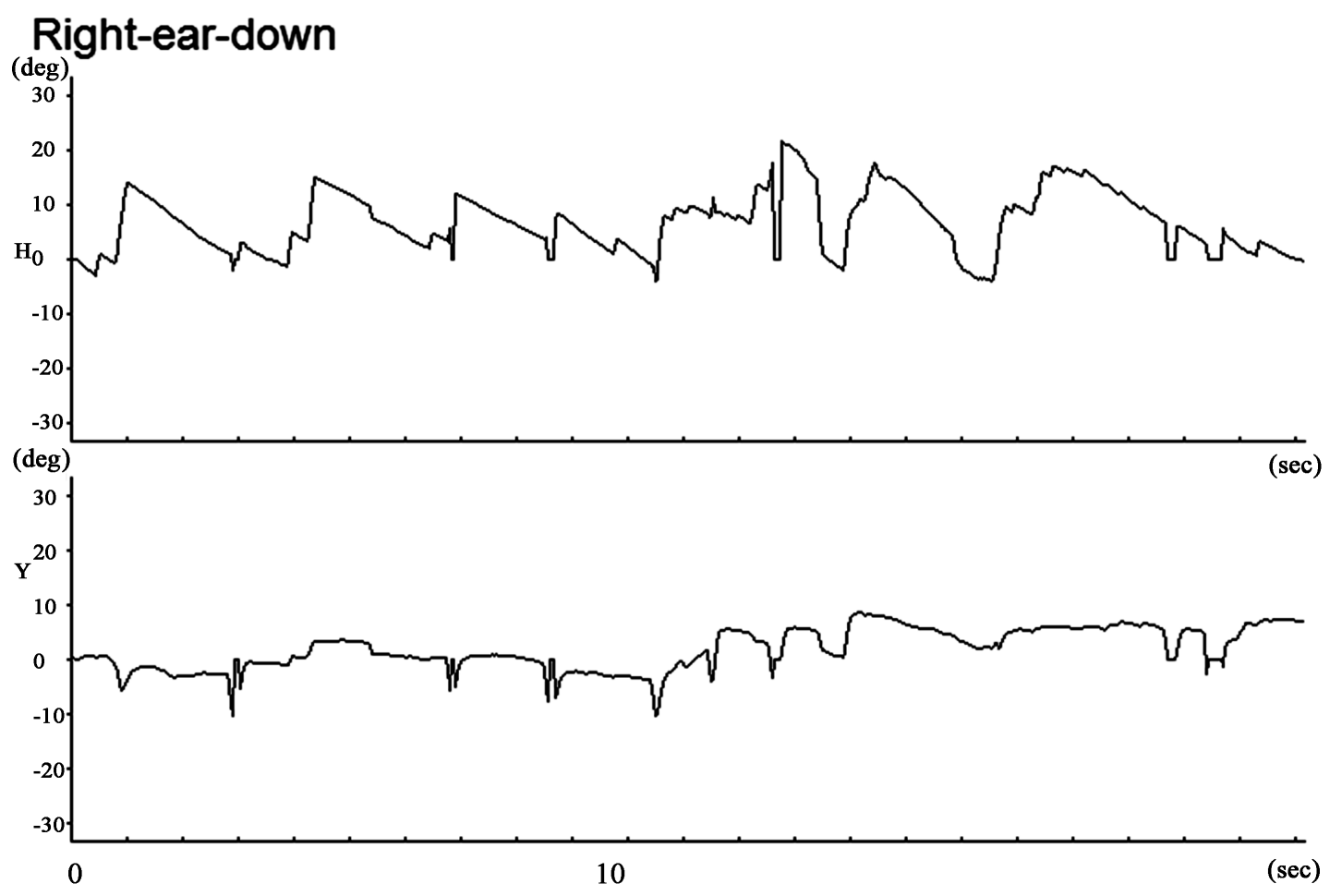

Figure 3. Video-oculography (position trace). In the right-ear-down position, nystagmus toward the right lasted for more than 1 minute. $\mathrm{H}$, horizontal component; $\mathrm{V}$, vertical component. 
On 12 December, 2011, the patient felt dizziness at the time of awakening and visited our hospital again. We detected mild rightward horizontal nystagmus (persistent) in the supine and right-ear-down position; however, one week later, dizziness and positional nystagmus had disappeared. One year after the onset, we confirmed no recurrence by telephone.

\section{Discussion}

We have examined 634 patients with peripheral positional vertigo for 12 years. Only $2(0.003 \%)$ of these patients were under 12 years old. One was a 10-year-old girl with horizontal canalolithiasis, and the other is the present patient, who revealed persistent direction-changing geotropic positional nystagmus. In cases of childhood vertigo, we have to take into account central disorders such as brain tumor. In this case, we diagnosed the patient with a peripheral disorder based on the fact that his examination results remained normal, except for positional nystagmus and caloric test.

Peripheral positional vertigo is classified as posterior semicircular canal type (so-called benign paroxysmal positional vertigo) or horizontal semicircular canal type. Positional nystagmus of the horizontal canal type is classified as direction-changing apogeotropic nystagmus (horizontal component is toward the ceiling) or direction-changing geotropic nystagmus (horizontal component is toward the Earth). There are two types of geotropic nystagmus: one is a transient type and the other is a persistent type. Horizontal canalolithiasis (moving debris) accounts for transient geotropic positional nystagmus; however, horizontal nystagmus, which persists without decreasing in intensity over time, cannot be explained by canalolithiasis. The pathophysiology of the persistent type of geotropic nystagmus is considered to be a result of light cupula of the horizontal canal [10]-[12]. In a supine position, permanent horizontal nystagmus toward the intact side is observed. In a neutral position, with the head turned $20^{\circ}-60^{\circ}$ to the affected side, the nystagmus decreases and eventually stops. With greater head-turn, nystagmus toward the Earth lasts for more than 1 minute. These phenomena are considered to indicate that the cupula is deflected by the buoyancy of attached light debris, which is less dense than the endolymph (Figure 4).

The biggest question is related to the identity of the light debris. One possibility is floating cells. In squirrel monkeys, Yamane and Igarashi [13] found monocytes and lymphocytes floating in the endolymphatic sac. If the same conditions occur in human labyrinth, free-floating cells would gradually swell up due to degeneration and decrease in density. Another likely explanation is that attached otoconia expand and decrease in density because direction-changing apogeotropic nystagmus (heavy cupula) sometimes changes to persistent direction-changing geotropic nystagmus. In the present patient, we speculate that free-floating light cells had adhered to the cupula of horizontal canal, because the patient has revealed persistent geotropic positional nystagmus since an early stage.

Although Hiruma et al. [14] considered that the density change of endolymph makes the cupula relatively light, this hypothesis cannot account for abrupt onset of vertigo. If endolymph becomes heavy, vertical semicircular canals are also influenced. Consequently, torsional/vertical (down beating) nystagmus should occur in the sitting position, because the cupula of superior canal moves toward the ampullofugal direction. Imai et al. [15] assumed that the denatured cupula or otolith imbalance is the pathophysiology of geotropic nystagmus with long time constant. However, otolith imbalance theory cannot explain the cessation of nystagmus in a neutral position, and there is no evidence that utricular dysfunction causes horizontal eye movements.
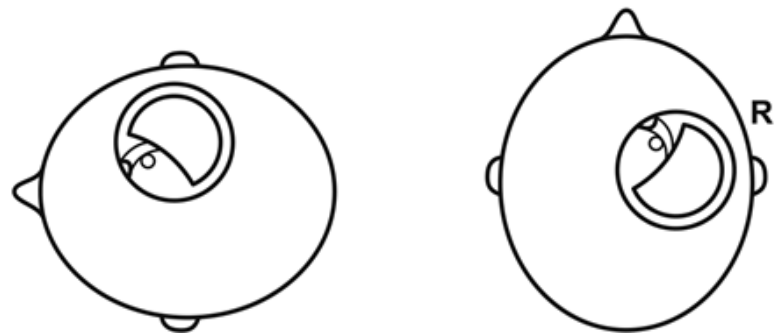

Neutral Position

Figure 4. Light cupula theory. Affected side is the right (R). Circles represent light debris. In the left-ear-down and supine positions, the cupula undergoes ampullofugal bending by the buoyancy. As a result, leftward nystagmus occurs. In the rightear-down position, the cupula undergoes ampullopetal deflection and rightward nystagmus occurs. 
The angle between the sagittal plane and the cupula of horizontal canal is thought to be approximately $20^{\circ}$ [16]; however, neutral position is sometimes wider than $20^{\circ}$ [14]. In the present case, neutral position was $45^{\circ}$. We cannot suggest the exact reason; however, the main reason may be interindividual differences. According to MRI study [17], the angle between the both posterior canals varied greatly (the mean value was $92.6^{\circ}$, and the standard deviation was $11.7^{\circ}$ ). We speculate that the angle between the sagittal plane and the cupula of horizontal canal also varies widely from person to person.

Although the rate of positivity of caloric test is not high in patients with positional vertigo [1], the present case showed obvious canal paresis of the right ear. Neutral position was the right side too. Therefore, we were convinced that the lesion was in the right horizontal semicircular canal. Because prominent nystagmus occurred in response to buoyancy, the mechanism of canal paresis was not damage of a sense organ, but central inhibition. We considered that the cerebellum suppressed the vestibular nucleus during the process of vestibular compensation.

At the second episode, we detected mild rightward horizontal nystagmus (persistent) in a supine position. It is hard to explain the reversal of nystagmus. Recovery nystagmus in vestibular neuronitis is similar phenomenon. We speculate that the reversal of nystagmus is a result of transient imbalance between the both vestibular nuclei, because vestibular compensation is not a single process but a complicated plasticity in the central nervous system [18].

\section{References}

[1] Baloh, R.W., Honrubia. V. and Jacobson, K. (1987) Benign Positional Vertigo: Clinical and Oculographic Features in 240 Cases. Neurology, 37, 371-378. http://dx.doi.org/10.1212/WNL.37.3.371

[2] Katsarkas, A. (1999) Benign Paroxysmal Positional Vertigo (BPPV): Idiopathic versus Post-Traumatic. Acta Otolaryngol, 119, 745-749. http://dx.doi.org/10.1080/00016489950180360

[3] Cohen, H.S. and Sangi-Haghpeykar, H. (2010) Canalith Repositioning Variations for Benign Paroxysmal Positional Vertigo. Otolaryngology—Head and Neck Surgery, 143, 405-412. http://dx.doi.org/10.1016/j.otohns.2010.05.022

[4] Korres, S., Balatsouras, D.G., Kaberos, A., Economou, C., Kandiloros, D. and Ferekidis, E. (2002) Occurrence of Semicircular Canal Involvement in Benign Paroxysmal Positional Vertigo. Otology \& Neurotology, 23, 926-932. http://dx.doi.org/10.1097/00129492-200211000-00019

[5] Prokopakis, E., Vlastos, I.M., Tsagournisakis, M., Christodoulou, P., Kawauchi, H. and Velegrakis, G. (2012) Canalith Repositioning Procedures among 965 Patients with Benign Paroxysmal Positional Vertigo. Audiology and Neurotology, 18, 83-88. http://dx.doi.org/10.1159/000343579

[6] vonBrevern, M., Radtke, A., Lezius, F., Feldmann, M., Ziese, T., Lempert, T., et al. (2007) Epidemiology of Benign Paroxysmal Positional Vertigo: A Population Based Study. Journal of Neurology, Neurosurgery \& Psychiatry, 78, 710-715. http://dx.doi.org/10.1136/jnnp.2006.100420

[7] Saka, N., Imai, T., Seo, T., Ohta, S., Fujimori, K., Masumura, C., et al. (2013) Analysis of Benign Paroxysmal Positional Nystagmus in Children. International Journal of Pediatric Otorhinolaryngology, 77, 233-236. http://dx.doi.org/10.1016/j.ijporl.2012.11.003

[8] Ikeda, T., Hashimoto, M., Horiike, O. and Yamashita, H. (2002) Simple Eye Movement Image Analysis Technique Using NIH IMAGE. Equilibrium Research, 61, 90-96. http://dx.doi.org/10.3757/jser.61.90

[9] Imai, T., Sekine, K., Hattori, K., Takeda, N., Koizuka, I. and Nakamae, K. (2005) Comparing the Accuracy of VideoOculography and the Scleral Search Coil System in Human Eye Movement Analysis. Auris Nasus Larynx, 32, 3-9. http://dx.doi.org/10.1016/j.anl.2004.11.009

[10] Hiruma, K. and Numata, T. (2004) Positional Nystagmus Showing Neutral Points. ORL; Journal of Oto-Rhino-Laryngology and Its Related Specialties, 66, 46-50. http://dx.doi.org/10.1159/000077234

[11] Bergenius, J. and Tomanovic, T. (2006) Persistent Geotropic Nystagmus-A Different Kind of Cupular Pathology and Its Localizing Signs. Acta Oto-Laryngologica, 126, 698-704. http://dx.doi.org/10.1080/00016480500475609

[12] Ichijo, H. (2012) Persistent Direction-Changing Geotropic Positional Nystagmus. European Archives of Oto-RhinoLaryngology, 269, 747-751. http://dx.doi.org/10.1007/s00405-011-1700-1

[13] Yamane, H. and Igarashi, M. (1984) Free-Floating Cells in the Endolymphatic Sac after Surgical Utricular Nerve Section. ORL; Journal of Oto-Rhino-Laryngology and Its Related Specialties, 46, 289-293. http://dx.doi.org/10.1159/000275726

[14] Hiruma, K., Numata, T., Mitsuhashi, T., Tomemori, T., Watanabe, R. and Okamoto, Y. (2011) Two Types of Direction-Changing Positional Nystagmus with Neutral Points. Auris Nasus Larynx, 38, 46-51. 
http://dx.doi.org/10.1016/j.anl.2010.07.004

[15] Imai, T., Takeda, N., Uno, A., Horii, A., Kitahara, T., Nishiike, S., et al. (2012) Benign Paroxysmal Positional Vertigo Showing Sequential Translations of Four Types of Nystagmus. Auris Nasus Larynx, 39, 544-548. http://dx.doi.org/10.1016/j.anl.2011.10.007

[16] Bisdorff, A.R. and Debatisse, D. (2001) Localizing Signs in Positional Vertigo Due to Lateral Canal Cupulolithiasis. Neurology, 57, 1085-1088. http://dx.doi.org/10.1212/WNL.57.6.1085

[17] Ichijo, H. (2002) Angles between Left and Right Vertical Semicircular Canals. Nippon Jibiinkoka Gakkai Kaiho, 105, 1138-1142. http://dx.doi.org/10.3950/jibiinkoka.105.1138

[18] Curthoys, I.S. and Halmagyi, G.M. (1995) Vestibular Compensation: A Review of the Oculomotor, Neural, and Clinical Consequences of Unilateral Vestibular Loss. Journal of Vestibular Research, 5, 67-107. http://dx.doi.org/10.1016/0957-4271(94)00026-X 